\title{
Cardiovascular Disease in Women with Chronic Renal Failure
}

\author{
NWAMAKA CHIJ I OKENZERE, ${ }^{1}$ CHUKWUBI KEUDOKA OKEKE ${ }^{2}$
}

\begin{abstract}
:
Objective: Patients with chronic renal failure have high burden of cardiovascular morbidity and mortality. This study was carried out to investigate the development of cardiovascular disease in chronic renal failure among female patients on dialysis treatment in Nigeria.

Materials and Methods: A total of 40 adult female subjects participated in this study. 20 of them were apparently healthy and served as control group while the rest 20 were female patients with chronic renal failure (CRF) on dialysis treatment. Fasting blood samples were collected and their lipid profile, Total Cholesterol (TC), Triglyceride (TG), High Density Lipoprotein -Cholesterol (HDL-C), Low Density Lipoprotein -Cholesterol (LDL-C), and Very Low Density Lipoprotein -Cholesterol (VLDL-C) were estimated using enzymatic methods. The percentages of these parameters in circulation were obtained. The cardiovascular risk ratios (TC/HDL-C and LDL-C/HDL-C) were calculated.

Result: The lipid profile of the chronic renal failure patients (TC $5.70 \pm 0.80 \mathrm{mmol} / \mathrm{l}, \mathrm{TG} 1.46 \pm 0.40 \mathrm{mmol} / \mathrm{l}, \mathrm{LDL}-\mathrm{C}$ $3.50 \pm 0.2 \mathrm{mmol} / \mathrm{l}$, and VLDL-C $0.67 \pm 0.2 \mathrm{mmol} / \mathrm{l})$ were significantly higher $(p<0.05)$ than that of control group (TC $4.03 \pm 0.13 \mathrm{mmol} / \mathrm{l}, \mathrm{TG} I .10 \pm 0.3 \mathrm{mmol} / \mathrm{l}, \mathrm{LDL}-\mathrm{C} 1.85 \pm 0.5 \mathrm{mmol} / \mathrm{l}$, and VLDL-C $0.50 \pm 0.01 \mathrm{mmol} / \mathrm{l})$ except HDL-C. $H D L-C$ of the $C R F$ patients $(I .40 \pm 0.2 \mathrm{mmol} / \mathrm{l})$ was significantly lower $(p<0.05)$ than that of healthy women $(H D L-C$ $1.70 \pm 0.04 \mathrm{mmol} / \mathrm{I})$. These depict no difference in the percentage of VLDL-C \& TG in circulation between the control (VLDL -C 5\% and TG 45\%) and chronic renal failure patients (VLDL -C 5\% and TG 44\%). In CRF group, it was observed that $28 \%$ of the total plasma lipid (I $2.73 \mathrm{mmol} / \mathrm{I})$ was LDL-C but in healthy women, percentage of LDL-C in circulation (out of $9.18 \mathrm{mmol} / \mathrm{l}$ ) was $20 \%$. It was also observed that II\% of the total plasma lipid (I2.73mmol/I) in CRF patients was HDL-C but in healthy subjects, the percentage of HDL-C in circulation (out of $9.18 \mathrm{mmol} / \mathrm{l}$ ) was 19\%. The cardiovascular risk indices (TC/HDL-C and LDL-C/HDL-C) of the CRF patients (TC/HDL-C 3.9I \pm 0.24 and

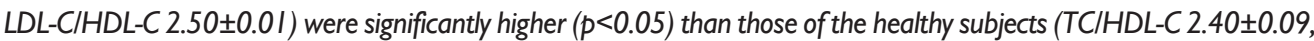
LDL-C/HDL-C I.10 0.08$)$.

Conclusion: These results indicate that chronic renal failure is a risk factor to development of cardiovascular disease in female patients on dialysis.
\end{abstract}

Key words: lipid profile, chronic renal failure, cardiovascular disease.

\section{Introduction:}

In ageing population, the absolute number of deaths due to cardiovascular disease in women is actually increasing. The risk factors for coronary heart disease in women are cigarette, smoking, hypertension, (including isolated systolic hypertension), dyslipidemia, diabetes mellitus, obesity, sedentary lifestyle, and poor nutrition. Although most risk factors for coronary heart disease are similar in men and women, gender differences have been documented, particularly diabetes and dyslipidemia. Patients with chronic kidney disease (CKD) have high burden of cardiovascular

1. Department of Medical Lab Sciences, Rivers State University of Science and Technology, Port Harcourt, Rivers State, Nigeria.

2. Department of Prosthesis and Orthopaedic Technology, Federal University of Technology,Owerri, Imo State, Nigeria.

Correspondence : Dr. Chukwubike Udoka Okeke, Department of Prosthesis and Orthopaedic Technology, Federal University of Technology, Owerri, Imo State, Nigeria. e-mail: jmdsph @yahoo.com. Phone: +2348037353551. morbidity and mortality. Once patients reach end stage kidney disease (CKD stage -5) and enter dialysis programs, they have an alarmingly high rate of cardiovascular death with those in the youngest age range of 25 years having equivalent cardiovascular mortality rate of 75 to 85 year olds in the general population. ${ }^{1}$ End stage renal disease (ESRD) is associated with accelerated atherosclerosis and premature death from cardiovascular disease. These events are driven by oxidative stress inflammation and lipid disorders. ESRDinduced lipid abnormalities primarily stem from dysregulation of high density lipoprotein (HDL), triglyceride-rich lipoprotein metabolism, and oxidative modification of lipoprotein. ${ }^{2}$ Hypertriglyceridemia, abnormal composition, and impaired clearance of triglyceride-rich lipoproteins and their remnants are mediated by down-regulation of lipoprotein lipase, hepatic lipase, very low density lipoprotein (VLDL) receptor, and LDL receptor-related protein, relative reduction in Apo C-II/Apo C-III ratio, up-regulation of acylCOA cholesterol acyl transferase, and elevated plasma level 
of cholesterol ester-poor prebeta HDL. The vast majority of patients with chronic kidney disease does not progress to end-stage renal failure but do have a significantly higher incidence of cardiovascular co-morbidities. ${ }^{3}$

Abnormal lipid metabolism in chronic renal failure is attributed to hormonal influence. Akmalet $\mathrm{al}^{4}$ stated that excess parathyroid hormone (PTH) adversely affect lipid metabolism in CRF. In their study, they observed that excess blood level of PTH and not other consequences of CRF are mainly responsible for the abnormalities in lipid metabolism, because excess PTH reduces post-heparin lipoprotein lipase (LPL) activity in plasma, which in turn results in impaired lipid removal from the circulation and consequently hyperlipidemia. Lee et $\mathrm{al}^{5}$ suggested from their study that low lysophosphatidylcholine, but not oxidixed LDL is associated with increased risk of CVD among a group of Korean haemodialysis patients.

Patients with abnormal kidney function are at a greatly increased risk of heart disease and subsequent death from cardiovascular causes. Manjunath et $\mathrm{al}^{6}$ from their study demonstrated that certain levels of dyslipidemia were indecently associated with renal replacement therapy and rapid renal progression in CKD stage 3-5. Multidetector computed tomographic angiography showed that mild and moderate pre-dialysis CKD are independent risk factors for coronary artery atherosclerosis. ${ }^{7}$

Cholesterol (one of the major lipid in lipoprotein) is both the substrate for, and the target of the steroidal sex hormones. ${ }^{8}$ It is on this premise that this study is carried out to investigate the development of cardiovascular disease in chronic renal failure among female gender.

\section{Materials and methods:}

A total of 40 adult female subjects were used in this study. 20 of them were apparently healthy females (control group), while the rest 20 were patients with chronic renal failure on dialysis treatment in Nigeria (CRF group). $5 \mathrm{ml}$ of blood sample collected from each subjects at fasting state (in the morning) was used to estimate the level of serum Total Cholesterol (TC), Triglyceride (TG), HDL-C, LDL-C, and VLDL-C using enzymatic method with Human Diagnostic test kit. ${ }^{9}$ The blood sample was collected after obtaining informed consent from the participants and Hospital management.

\section{Statistical analysis:}

The data collected after biochemical analysis was subjected to statistical calculation using statistical software (Megastat). The mean, standard deviation/ standard error of mean (s.e), F-distribution test were obtained. Critical value or test of probability less than $0.05(\mathrm{p}<0.05)$ was regarded significant.

\section{Results:}

The lipid profiles of the chronic renal failure patients (TC $5.70 \pm 0.80 \mathrm{mmol} / \mathrm{l}, \mathrm{TG} 1.46 \pm 0.40 \mathrm{mmol} / \mathrm{HDL}-\mathrm{C} 1.40 \pm 0.2 \mathrm{mmol} /$ 1, LDL-C 3.50 $\pm 0.2 \mathrm{mmol} / \mathrm{l}$, and VLDL-C $0.67 \pm 0.2 \mathrm{mmol} / \mathrm{l}$ ), as shown in Table 1 , were significantly $(\mathrm{p}<0.05)$ altered when compared with those of the healthy subjects (TC $4.03 \pm 0.13 \mathrm{mmol} / \mathrm{l}, \mathrm{TG} 1.10 \pm 0.3 \mathrm{mmol} / \mathrm{l}, \mathrm{HDL}-\mathrm{C} 1.70 \pm 0.04 \mathrm{mmol} /$ 1, LDL-C $1.85 \pm 0.5 \mathrm{mmol} /$, and VLDL-C $0.50 \pm 0.01 \mathrm{mmol} / \mathrm{l})$.

Table-I

The means \pm s.e ( $\mathrm{mmol} / \mathrm{l})$ of lipid profile of the subjects.

\begin{tabular}{lcccccc}
\hline GROUPS & TC & TG & HDL-C & LDL-C & VLDL-C & Total lipid \\
\hline Control group & $4.03 \pm 0.13$ & $1.10 \pm 0.3$ & $1.70 \pm 0.04$ & $1.85 \pm 0.5$ & $0.50 \pm 0.01$ & 9.18 \\
CRF group. & $5.70 \pm 0.80$ & $1.46 \pm 0.40$ & $1.40 \pm 0.2$ & $3.50 \pm 0.2$ & $0.67 \pm 0.2$ & 12.73 \\
P-value & $\mathrm{p}<0.05$ & $\mathrm{p}<0.05$ & $\mathrm{p}<0.05$ & $\mathrm{p}<0.05$ & $\mathrm{p}<0.05$ & $\mathrm{p}<0.05$ \\
\hline
\end{tabular}

Table-II

The Cardiovascular risk indices (TC/HDL-C and LDL-C/ HDL-C) of the subjects.

\begin{tabular}{lcc}
\hline Groups & TC/HDL-C & LDL-C/HDL-C \\
\hline Control group & $2.40 \pm 0.09$ & $1.10 \pm 0.08$ \\
CRF group & $3.91 \pm 0.24$ & $2.54 \pm 0.21$ \\
P-value & $\mathrm{P}<0.05$ & $\mathrm{P}<0.05$ \\
\hline
\end{tabular}

The cardiovascular risk indices, TC/HDL-C and LDL-C/HDL$\mathrm{C}$, of the chronic renal failure patients (TC/HDL-C 3.91 \pm 0.24 and LDL-C/HDL-C 2.50 \pm 0.01 ) as shown in Table 2, were significantly higher $(\mathrm{p}<0.05)$ than those of the healthy

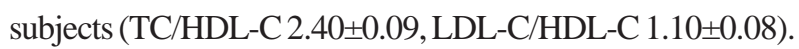

In figure 1 and 2, there was no difference in the percentage of VLDL-C\& TG in circulation between the control (VLDL C 5\% and TG 45\%) and chronic renal failure patients (VLDL -C 5\% and TG 44\%). 


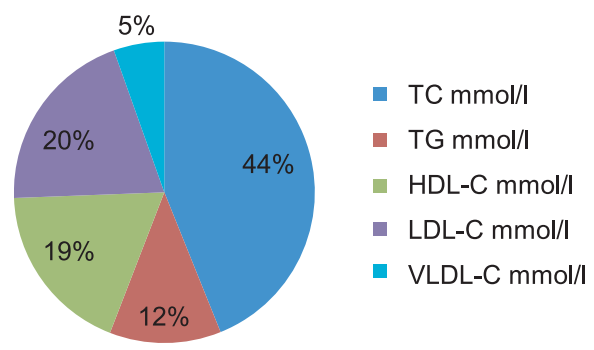

Fig.-1: The pie chart of the lipid profile of the control group

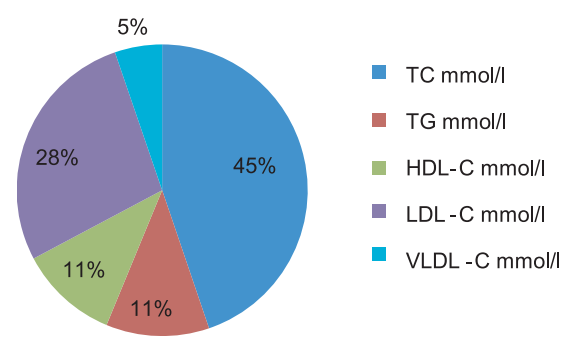

Fig.-2: The pie chart of the lipid profile of the CRF group

In CRF group, it was observed that $28 \%$ of the total plasma lipid $(12.73 \mathrm{mmol} / \mathrm{l})$ was LDL-C but in control group, percentage of LDL-C in circulation (out of $9.18 \mathrm{mmol} / \mathrm{l}$ ) was $20 \%$. It was also observed that $11 \%$ of the total plasma lipid (12.73mmol/l) was HDL-C but in control group the percentage of HDL-C in circulation (out of $9.18 \mathrm{mmol} / \mathrm{l}$ ) was $19 \%$.

\section{Discussion:}

It was observed in this study that the percentage composition of lipid parametersas shown in figure 1 and 2 indicated no difference in percentage of plasma TG and VLDL-C components in circulation though the concentrations of these parameters (in $\mathrm{mmol} / \mathrm{l}$ ) showed a significant higher level $(\mathrm{p}<0.05)$ in CRF patients than that of the control subjects. This finding indicated that relative percentage of TG and VLDL-C in circulation among female patients on dialysis would not give a clear metabolic effect of renal failure on these parameters and secondly, it showed that transportation of these lipids in plasma are of equal percentage irrespective of the renal damage.This abnormality in TG and TG-rich lipoprotein stems from dysregulation of these lipid and oxidative modification of lipoprotein. ${ }^{2}$ Eknoyan ${ }^{10}$ said that the reduced catabolism of lipoprotein that are rich in TG is an early fundamental disturbance of lipoprotein metabolism in renal disease, but clinical evidence suggests that this is not necessarily linked to increased plasma concentration of TG.
Total cholesterol (TC) and other cholesterol- rich lipoproteins (HDL-C and LDL-C) of the renal failure patients (TC $5.70 \pm 0.80 \mathrm{mmol} / \mathrm{l}$, HDL-C $1.40 \pm 0.2 \mathrm{mmol} / \mathrm{lm}$ and LDL-C $3.50 \pm 0.2 \mathrm{mmol} / \mathrm{l})$ showed a significant difference $(\mathrm{p}<0.05)$ in plasma concentration (in $\mathrm{mmol} / \mathrm{l}$ ) than that of the healthy females (TC $4.03 \pm 0.13 \mathrm{mmol} / \mathrm{l}$, HDL-C $1.70 \pm 0.04 \mathrm{mmol} / \mathrm{l}$ and LDL-C $1.85 \pm 0.5 \mathrm{mmol} / \mathrm{l})$. It was observed in this study that $45 \%$ of Total plasma lipid (12.73mmol/l) was Total Cholesterol (TC) in renal failure patients while $44 \%$ of Total plasma lipid $(9.18 \mathrm{mmol} / \mathrm{l})$ was Total cholesterol in the healthy females.Going by the percentage level of TC, there was no significant difference ( $>>0.05$ ). HDL-C and LDL-C levels of the renal failure patients showed a great differencein percentage (HDL-C 11\% and LDL-C 27\%) than that of the healthy females (HDL-C 19\% and LDL-C 20\%). This showed that in CRF, despite high level of Total plasma lipid $(12.73 \mathrm{mmol} / \mathrm{l})$, lower percentage of HDL-C and higher percentage of LDL-C were in circulation unlike the healthy patients (total plasma lipid $9.18 \mathrm{mmol} / \mathrm{l}$ ) with higher percentage of HDL-C and lower percentage of LDL-C in circulation. This indicated that in CRF, there was development of atherosclerosis/CVD. Vaziri ${ }^{2}$ stated that ESRD-induced lipid abnormalities primarily stem from dysregulation of HDLC, TG-rich lipoprotein metabolism, and oxidative modification of lipoprotein. Significant higher levels of TC/HDL-C and LDL-C/HDL-C ratio in CRF patients also indicated that development of CVD or atherosclerosis in CRF patients. Akmalet $\mathrm{al}^{4}$ stated excess parathyroid hormone (PTH) in CRF adversely affects lipid metabolism. They stated that excess PTH reduces post heparin lipoprotein lipase activity in plasma which in turn results in impaired lipid removal from the circulation. High level of LDL-C and low HDL-C are implicated in development of atherosclerotic CVD ${ }^{11,12}$ and the higher the ratio of LDL-C to HDL-C the higher the risk of developing CVD.

In conclusion, women with chronic renal failure (on dialysis treatment) develop atherosclerotic cardiovascular disease.

\section{Conflict of interest: None.}

\section{References:}

1. Bagdade J,Casaretto A, Albers J: Effects of chronic uremia, haemodialysis and renal transplantation on plasma lipid proteins in man. J Lab Clin Med. 1976; 87: 37-48.

2. Vaziri ND: causes of dysregulation of lipid metabolism in chronic renal failure. Semin Dial. 2009; 22(6): 644-651.

3. Wright J, Hutchison A,: Cardiovascular disease in patients with chronic kidney disease. Vasc Health Risk Manag. 2009; 5: 713-722. 
4. Akmal M, Kasim SE, Soliman AR, MassrySG. Excess parathyroid hormone adversely affects lipid metabolism in chronic renal failure, Kidney International, 1990; 37: 854858.

5. Lee YK, Lee DH, Kim JK, Park MJ, Yan JJ. Vaziri ND, Noh JW. Lysophosphatidylcholine, Oxidized Low Density Lipoprotein and cardiovascular Disease in Korean Hemodialysis Patients: Analysis at 5 Years of Follow-up, J Korean Med Sci. 2013; 28(2): 268-273.

6. Manjunath G, Tighiouart H, Ibrahim H, et al. level of kidney function as a risk factor for atheriosclerotic cardiovascular outcomes in the community. J Am Coll Cardiol. 2003; 41: 47-55.

7. Roy SK, Cespedes A, Li D, Choi TY, BudoffMJ: Chronic kidney disease is associated with increased coronary artery atherioscerosis as revealed by multidetector computed tomographic angiography, Tex Heart Inst J.2012; 39(6): 811-816.

8. Gevers-leuven J. Sex steroids and lipoprotein metabolism. Pharmacology \& Therapeutics, 1994; 64(1): 99-126.

9. Human Gesellschaft fur Biochemica and DiagnosticambH, Max-Planck-Ring 21. D-65205 Wiesbaden Germany.

10. Ekonoyan G. The epidemic of cardiovascular disease in patients with chronic renal disease. American Journal of Kidney Disease 1998; 32: 3-5.

11. Bukachi F, Rana BS and Henein MY. Lowering cholesterol in patients with coronary artery disease. African Health, 2000; 22 (2):16-18.

12. MJafi. Lipid profile in transplant patients. New England Journal of Medicine, 2003; 323: 604-614. 